\title{
AS CONTRADIÇÕES DA TEMPORALIDADE PÓS-MODERNA, À LUZ DA PANDEMIA DO NOVO CORONAVÍRUS
}

\author{
LAS CONTRADICCIONES DE LA TEMPORALIDAD POST-MODERNA, A LA LUZ DE \\ LA NUEVA PANDEMIA DEL CORONAVIRUS
}
THE CONTRADICTIONS OF POST-MODERN TEMPORALITY IN THE LIGHT OF THE NEW CORONAVIRUS PANDEMIC

\author{
Eduardo DUQUE ${ }^{1}$ \\ José Francisco DURÁN VÁZQUEZ ${ }^{2}$
}

RESUMO: Neste artigo reflete-se sobre o quanto vivemos numa época de crescente complexidade, que parecia já ter superado todos os problemas, dada a segurança que a confiança nos processos científicos e tecnológicos parecia ter-nos devolvido. Mas quando estes processos, como agora acontece na pandemia de Coronavírus, mostram a sua fragilidade, eles revelamnos, como nunca tinha acontecido, as suas debilidades. Fraquezas essas que resultam de depositar todo o valor objetivo nesses processos, acreditando que neles estava a capacidade de nos redimir de todos os nossos males. O correr atrás da inovação e do sucesso a todo o custo, sem ética, sem respeito pela natureza e pelos outros, sem consideração pelo passado e sem nele ancorar o futuro, reduz a estabilidade e a segurança estrutural das sociedades e dos indivíduos que as compõem.

PALAVRAS-CHAVE: Tempo. Temporalidades. Mudança social. Pandemia. COVID-19.

RESUMEN: En este artículo se reflexiona sobre el modo en que habitamos una época de creciente complejidad, que semejaba haber superado todos los problemas, dada la seguridad y la confianza que parecian conferirnos los procesos científicos y tecnológicos. No obstante, cuando estos procesos, como ocurre ahora en la pandemia de Coronavirus, muestran su fragilidad, revelan, como nunca anteriormente, sus debilidades. Debilidades que son la consecuencia de depositar todo el valor objetivo en dichos procesos, creyendo que en ellos estaba la capacidad de redimirnos de todos nuestros males. Haber perseguido la innovación y el éxito a toda costa, sin demasiados principios éticos, ni respeto por la naturaleza y por nuestros congéneres; sin tener en cuenta el pasado ni anclarse en el futuro, ha reducido la estabilidad y la seguridad estructural de las sociedades y de los individuos que las integran.

PALABRAS CLAVE: Tiempo. Temporalidades. Cambio social. Pandemia. COVID-19.

\footnotetext{
${ }^{1}$ Universidade Católica Portuguesa (UCP), Braga - Portugal. Professor da Faculdade de Filosofia e Ciências Sociais. Membro Integrado do Centro de Estudos de Comunicação e Sociedade da Universidade do Minho (UM). Doutorado em Sociologia (UCM) - Espanha. ORCID: https://orcid.org/0000-0003-4719-3148. E-mail: eduardoduque@ucp.pt

${ }^{2}$ Universidade de Vigo (UVIGO), Vigo - Espanha. Professor de Sociologia. Doutorado em Sociologia. ORCID: https://orcid.org/0000-0002-7440-0168. E-mail: joseduran@uvigo.es
}

RIAEE - Revista Ibero-Americana de Estudos em Educação, Araraquara, v. 16, n. 3, p. 1713-1729, jul./set. 2021. e-ISSN: 1982-5587 
ABSTRACT: This article reflects on how much we live in a time of increasing complexity, which seemed to have already overcome all problems, given the security that confidence in scientific and technological processes seemed to have returned to us. But when these processes, as now happens in the Coronavirus pandemic, show their weakness, they reveal, as never before, their weaknesses. These are the weaknesses that result from depositing all the objective value in these processes, believing that in them was the capacity to redeem us from all our ills. Running after innovation and success at all costs, without ethics, without respect for nature and for others, without regard for the past and without anchoring the future in it, reduces the stability and structural security of the societies and individuals that compose them.

KEYWORDS: Time. Temporalities. Social change. Pandemic. COVID-19.

\section{Sem o tempo, seria inconcebível a mudança social}

O ser humano, ao longo da história, sempre desejou compreender o tempo, de forma a antever o futuro (BOURDIEU, 1998). Para isso, as sociedades tradicionais serviam-se de oráculos e profecias. O homem moderno impôs um conhecimento metódico, assente na razão científica, recorrendo com frequência ao planeamento e à prospetiva. O futuro resiste a prognósticos fáceis e dóceis, por motivos do tipo estrutural, relacionados com a natureza da sociedade (RAMOS, 2007). Contudo, o dinamismo da modernidade necessita e quer conhecêlo. Quem se limita ao que está a acontecer nem sequer compreende o que acontece. A imaginação substituiu boa parte do espaço dado à observação (ROUANET, 2012). O futuro transformou-se num tempo enigmático, devido à complexidade do mundo, opaco e incaptável, voltado para a inovação e entretecido numa teia de interdependências. A antevisão e prospetiva podem estar afastadas das nossas capacidades, em virtude da sua irredutível incerteza.

O homem sempre se muniu de instrumentos (meios) de previsão do futuro, mas esbarrou no elemento de inovação e imprevisibilidade, impedindo-o de obter proteção contra certezas absolutas e surpresas.

O esquema tradicional e arcaico, baseado em conceções de transformações rituais dos ciclos em círculos e de modelos originais, neutraliza o carácter de futuro aberto, concebendo-o como continuação do presente (ELCHARDUS; SMITS, 2006). Aqui, impera o reino do destino já escrito e não conhecido (ELIAS, 1989; HUBERT, 1992; SUE, 1995).

Eis aqui - escreve Marco Aurélio nas suas Meditações - as propriedades da alma razoável, ela viaja pelo mundo inteiro e pelo vazio que a rodeia; examina a sua configuração; a sua visão estende-se para a eternidade; ela abraça e aprecia a renovação periódica do universo; ela acredita que aqueles que virão depois de nós não verão nada de novo, como aqueles que vieram antes de nós não viram nada além do que vemos agora, e que um homem que viveu quarenta anos, por pouco que tenha entendido, viu pouco mais ou menos 
quanto o precedeu e o que se seguirá, pois tudo continua uniformemente (MARCO AURÉLIO, 2004, Livro XI).

É, portanto, o passado da tradição que guia e dá sentido à vida, proporcionando segurança ao presente e ao futuro, percebidos em relação a um passado já conhecido. "Somente quem tem a tradição tem a medida", escreveu o poeta grego Teognis (JAEGER, 1996, p. 191). Uma medida que dá profundidade ao tempo. A origem da cidade de Roma - ab urbe conditasignificava precisamente a ligação a um tempo fundacional, a um princípio que desdobra o significado da história, projetando-o no presente e no futuro (REVAULT D'ALLONNES, 2008, p. 73).

O contexto estabelecido dava confiança a possibilidades de descobrir o segredo do destino e de adivinhar o além do presente: profecias, adivinhações, vaticínios, oráculos e visionários. O futuro estava latente e o esforço era dirigido para o descobrir, adivinhar, no sentido de alterar um destino a que não se podia fugir. Platão assim referia:

Não viste que, quando pratica por muito tempo e desde a infância, a imitação se infiltra no corpo, na voz, no modo de ser, e transforma o caráter alterando a sua natureza? (PLATÃO, 2003, p. 187)

Contrariamente ao tempo platônico, a contemporaneidade reivindica para si um modo próprio de fazer e construir o futuro. Revoltou-se contra a fatalidade de um destino inexorável e sem capacidade de intervenção. Ela quer construir um futuro humanamente configurável, aberto e indeterminado pela individualidade de cada sujeito (BAUMAN, 2000; SENNET, 2007). O olhar para o horizonte permite-lhe a prospetiva, as previsões científicas, a planificação política e a previsão econômica.

O futuro passa assim a ser sujeito de esboço, projeto, plano, gestão e regulamento. Os especialistas observam o presente para produzir o futuro desejado. Num mundo moderno, mecanicista, linear de causas e efeitos, a capacidade de projetar o futuro era uma metáfora poderosa de antevisão dos processos sociais e organizativos, bem como de realidades físicas (KOSELLECK, 1993; NOWOTNY, 1994). Esta metáfora converteu-se na palpável realidade quotidiana para a maioria da população, quando o desenvolvimento da sociedade do trabalho, primeiro, e a do consumo, depois, abriram às novas classes médias uma possibilidade nunca vista de realização pessoal (BURY, 2009; POMIAN, 1984).

Na contemporaneidade, a evolução entende o futuro como uma complexa cadeia de acontecimentos de vários significados e apenas com hipóteses de antevisão por indagação sobre o possível e verosímil e, neste aspeto, o nosso conhecimento torna-se muito débil. 
Não sendo o futuro a reposição do presente (Luhmann, 1996), mas algo desconhecido, fundado na inovação, a abertura ao futuro significa inevitavelmente um projeto vacilante. Se se conhecesse o dia de amanhã, ele seria um presente contínuo e não seria o futuro. Sucede como se o presente estendesse o seu horizonte a tal ponto que permitisse vislumbrar o futuro como um presente iminente (NOWOTNY, 1994).

Assim, acontece, de forma sincrónica, o campo de projeção de esperanças e medos, um cenário de batalha. A prospetiva social está eivada de referências positivas, como a esperança, e negativas, como o medo (INNERARITY, 2011).

\section{Da tomada de decisão à elaboração do sentido}

O indivíduo contemporâneo está sobrecarregado de decisões, levando a que este se apavore e tenha modos irracionais de se comportar. Quando tal acontece, deixa de haver o distanciamento necessário para a tomada de boas decisões, já que a pessoa perde as suas bases de estabilidade e, naturalmente, torna-se desorientada e insegura, perdendo como que o sentido das suas ações e, no limite, o sentido da sua vida (ARIÈS, 1988; GIDDENS, 1991).

Os efeitos negativos de uma sociedade que obriga à tomada urgente de decisões são visíveis na cultura hodierna, observa-se no modo de governar e das organizações. Como refere Innerarity (2011), quem tem grandes responsabilidades de decidir, tem que o fazer muitas vezes de forma imprevista e nem sempre com toda a informação ou compreensão dos fenômenos pelos quais está a decidir.

Até se poderia dizer que, atendendo aos custos da decisão e da responsabilidade seria mais adequado, por vezes, ter um leque com menos opções do que muitas oportunidades. Claro que o risco da opção aumenta, mas por outro lado também supõe maior liberdade na ação. A tomada de decisão implica precisamente a ousadia da escolha. Porque, de fato, à medida que os dias da pandemia de coronavírus se tornam evidentes, quando a sociedade enfrenta grandes riscos, não há mais opção a considerar, só é possível agir, tomar decisões. Mas toda a ação abre também caminho para a esperança, para o que fazer e, certamente, algo pode ser feito. Tudo isso requer a necessária confiança. E isso só pode surgir do mundo que nós, seres humanos, temos em comum. É assim que podemos prometer que não voltaremos a fazer o que fizemos ou que o faremos e continuaremos a fazer (ARENDT, 1998, p. 262). A confiança nasce assim da nossa condição temporal e mundana. Remete-nos do presente ao passado, para negá-lo ou afirmá-lo, e dali também para o futuro para decidir se devemos continuar ou começar de novo. 
A sociedade moderna tem sido, por norma, uma sociedade otimista, com uma abertura a novas possibilidades da autoconfiguração, ainda que algumas vezes sejam surpreendidos como o contrário. Como refere Innerarity (2011, p. 70), “uma sociedade democrática é uma sociedade em que aumenta o âmbito do que tem de ser decidido, mas estas decisões não são decisões soberanas, exercem-se num tecido em que os autores políticos dependem, por sua vez, da ação de muitos autores".

Os decisores sociais, na urgência da decisão, têm que ponderar o motivo da tomada de decisões de acordo com os critérios de racionalidade, da complexidade social, da configuração temporal e espacial, etc., conscientes de que todos estes critérios são interdependentes e justificam-se porque as sociedades contemporâneas estão todas elas ligadas na mesma teia.

Nas sociedades tradicionais uma determinada tomada de uma decisão, por regra, não interferia com o outro, porque todos os processos eram demasiado estanques, mas, nas sociedades complexas, os atos não são isolados, mas socialmente interdependentes (ADAM, 2003; 2004; URRY, 2002; VIRILIO, 1997). Para isso, muito contribui a informação de que hoje se dispõe.

O excesso de informação típico das sociedades funcionalmente diferenciadas - que é, muitas vezes, lacunas e fake news -, em vez de gerar mentes esclarecidas, produz sociedades ambíguas e incertas. É necessário estar atento à informação que se recebe, de modo a saber administrá-la.

Não são os sistemas de informação que originam uma diminuição do fluxo informativo (THOMPSON, 1998), pelo contrário, este é resultado de um saber selecionar amadurecido. Portanto, as nossas sociedades não podem ignorar a elaboração da informação, de forma a que ela possua e conceba, mesmo que implicitamente, estruturas de sentido.

Assim, podemos dizer que estamos diante de um jogo e, através das informações que chegam até nós, podemos ganhar ou perder.

\section{Investir no presente para vislumbrar o futuro}

As sociedades complexas estão envolvidas num sistema de interdependências de fatos encadeados que, numa primeira análise, se afiguram ingovernáveis, o que condiciona a questão da responsabilidade, da qual ninguém gosta de prestar contas. Neste sentido, é urgente trabalhar a capacidade de leitura e antecipação das consequências, as quais devem atender à leitura dos sinais atuais, de forma a evitar que não se entre somente em ação quando a crise se torna absolutamente presente. Sempre que tal acontecer, significa que as sociedades não estão 
devidamente preparadas para enfrentar os ventos do futuro (RICOTTA, 2006) que, sabemos bem, exigirão muita sapiência, mas também humildade para saber aceitar que há muitos elementos que, por mais fáceis que sejam de leitura, continuam, aos olhos do tempo presente, muito impenetráveis: são tempos espessos, que exigem mais tempo para neles se entrar.

Os tempos presentes exigem que construamos uma responsabilidade comum. Como dizia Arendt (1973, p. 283) em The Origins of Totalitarianism: "O caso de um só é o caso de todos", o que acontecerá mais pela iniciativa e pelo dom de cada um do que pela uma via normativa. Por esta mesma razão, diz-nos Innerarity (2011), é que as crises financeiras ou de saúde coletiva são um exemplo de como é difícil remeter os prejuízos coletivos para causas identificáveis ou atuar com critérios morais no meio destes processos num mundo em onde todos somos interdependentes, o que aumenta o número de irresponsabilidades e de ações que não são facilmente imputáveis. Para Innerarity (2011, p. 90):

[...] o problema está em como representar essa responsabilidade num momento em que perdeu evidência a relação entre o meu comportamento individual e os resultados globais, de aí que se torna urgente elaborar um conceito de responsabilidade que atenda à atual complexidade social e corresponda às nossas expectativas razoáveis de conseguir um mundo que possa ser governado e pelo qual nos responsabilizemos.

A responsabilidade a que se apela aqui será, então, muito mais ampla; que contempla efeitos não desejados, imprevisíveis e desconhecidos que não podem ser imputados aos autores, o que quer dizer que os limites da imputação terão de ser alargados para lá do horizonte do saber e da experiência, do modelo tradicional de controle sobre as formas triviais da ação, para a responsabilidade que parte dos processos complexos, em que há auto-organização e interações hierárquicas.

Neste mesmo sentido, nas sociedades complexas, aquelas que se prepararam para deixar entrar o futuro, ou seja, quem tem o poder, terá que o reorientar facilitando dinâmicas criativas, processos abertos e transparentes, terá que ter capacidade de gerir riscos individuais e coletivos e atender à segurança como um bem precioso.

Desta forma, é preciso trabalhar no tempo presente a responsabilidade do tempo futuro. Não se pode continuar a agir como que só houvesse presente, é necessário ser mais audaz e dar um passo, partilhando a responsabilidade de hoje com a do dia de amanhã.

É necessário - nas palavras de Arendt (1999, p. 106-107) - "estabelecer no oceano da insegurança do futuro ilhas de segurança". E para isso, temos que contar não apenas com a possibilidade de prometer, com confiança, o que se pretende fazer no futuro, mas também com a possibilidade de perdoar o que foi feito no passado. Assim, longe de cortar os laços com o 
pretérito, o que fazemos, deste modo, é libertar-nos das suas amarras, tornando possível um novo começo que nos permita enfrentar com confiança o presente e o futuro.

O ser humano torna-se, assim, melhor pessoa e vive o tempo presente não como quem está sempre a pagar as obrigações do tempo passado, mas como quem quer ganhar o tempo futuro. Precisa-se, portanto, de assumir uma responsabilidade prospetiva que anteveja, previna e configure respostas mais inteligentes capazes de responder aos novos desafios.

Finalmente, neste presente com os olhos no futuro, seria bom que a consciência da limitação do nosso saber face à imprevisibilidade do futuro se torne arma de combate contra as políticas imperialistas e de arrogância que se impõem sobremaneira nas nossas sociedades.

\section{A desconfiança perante a ação política}

A ação política mergulhou numa fase de grandes limitações, uma vez que a figura do herói foi aniquilada e os discursos épicos que anunciam as crises deixaram de atrair os cidadãos. Neste sentido, estamos perante um presente extasiado de mediocridade, onde os discursos heroicos já não mobilizam nem desinstalam e, até mesmo pelo contrário, são voltados ao indiferentismo e ostracismo.

Perante tal cenário, surge a necessidade de novos paradigmas, que sejam capazes de dar respostas às novas circunstâncias. Paradigmas que mobilizem as pessoas, que as façam levantar por novas causas, que as motivem a sair de suas casas, casas essas que as deixam confinadas ao conforto

O conforto, típico da nossa sociedade, não ajuda à transformação da comunidade. Ajuda, isso sim, a alimentar os egos, suscita o individualismo e absolutiza formas de pensar muito solipsísticas. Por isso, propõe-se políticas que eliminem os acordos absolutos e que superem as divergências absolutas. O que urge, de facto, são projetos sem predeterminação, mas sempre abertos a novas formulações e alternativas, projetos peregrinos de novos saberes, prontos para acolher ideias de todos os quadrantes.

Neste contexto, surge a necessidade de uma revolução copernicana, capaz de modificar em profundidade o modo de conceber política. $\mathrm{O}$ enquadramento clássico que, como todos perceberam, já não dá respostas. O governo tem que governar e não governar-se. Tem de investir nas pessoas, de ver mais à frente, deixando cair os populismos. Tem de estabelecer fortes laços com o futuro, que não é planificável nem fruto de adivinhação e, por isso, não há tempo para os amadorismos, é preciso gente que seja gente. Gente que estude, que respeite o peso do voto e que queira construir pontes para os que vêm depois de nós. 
O futuro é algo de novo, que vem ao encontro do ser humano, daí a necessidade de o antecipar com coração aberto e transparente. Trata-se de um jogo inteligente, lançado através da inteligência humana, sem viciação, onde todos os seres humanos jogam em relação e cujo resultado final, fruto da complexidade das interações, ainda não está determinado. Determinase, no dia-a-dia.

A forma de operar na política, muitas vezes atabalhoada, sem transparência e sem verticalidade, está muito distante das exigências dos novos tempos. É preciso, portanto, suscitar nas nossas sociedades um novo paradigma social! É preciso superar, em definitivo, o ambiente geral de crise em que a modernidade ocidental se instalou (ROSA, 2019). Mas também é necessário transcender tanto o diagnóstico da crise como a resposta do contínuo reformismo inovador (LE GOFF, 2002). Um reformismo que apenas repara a urgência do momento, no imediatismo do presente, quebrando toda a consciência do passado, sem a qual não pode haver um projeto do presente nem de futuro. Porque, de facto, somente a partir da perspetiva do antigo, o novo pode dar à luz uma outra vida, precisamente porque "se desprende de tudo o que havia" (ZAMBRANO, 1992, p. 14). Somente assim, poderemos sair da incerteza que nos envolve. Como refere Bauman (2001, p. 170):

\begin{abstract}
A incerteza do presente é uma poderosa força individualizadora. Ela divide em vez de unir, e como não há maneira de dizer quem acordará no próximo dia em qual divisão, a ideia de "interesse comum" fica cada vez mais nebulosa e perde todo valor prático. [...] Os medos, ansiedades e angústias contemporâneos são feitos para serem sofridos em solidão. Não se somam, não se acumulam numa "causa comum", não têm endereço específico, e muito menos óbvio.
\end{abstract}

Este processo é alimentado pela própria lógica dos sistemas democráticos que, por um lado, têm que tomar decisões com a rapidez exigida pelo ritmo acelerado das sociedades pósindustriais e, por outro lado, eles próprios favorecem, com as suas performances, a mesma dinâmica. Portanto, qualquer sensação de desaceleração deste movimento é interpretada como um sintoma de crise, que é - diga-se - a única interpretação possível para o referido abrandamento, pelo que rapidamente se volta a retomar o ritmo frenético, delirante, a toda a velocidade, porque é a este ritmo que a sociedade contemporânea se habituou a resolver as suas crises (HAN, 2016). Justamente por este motivo, a política e a gestão democráticas são direcionadas para continuar a acelerar o ritmo, e isso é afirmado repetidamente pelos líderes políticos. "Na pós-modernidade - escreve Harmut Rosa - a possibilidade da condução política do desenvolvimento da sociedade... tornou-se questionável: a política já não aparece como o marca-passo da sociedade, mas como o corpo de bombeiros que fica para trás e procura sair do 
problema" (ROSA, 2019, p. 287-288). Gera-se, assim, uma espiral em crescimento contínuo, que se retroalimenta com a sua própria energia e que nunca parece estar satisfeita. A matéria de que se nutre não é outra senão o desejo de superar a situação anterior, que é rapidamente dominada por outra, anunciada como ameaçadora. Tudo isto gera uma inquietude enorme que impulsiona de novo a mesma dinâmica, elevada ao princípio moral da pós-modernidade.

Como nos advertiram Adorno e Horkheimer (1995, p. 126):

A máquina gira sem sair do lugar. Ao mesmo tempo que já determina o consumo, ela descarta o que ainda não foi experimentado porque é um risco. [...] Nada deve ficar como era, tudo deve estar em constante movimento. Pois só a vitória universal do ritmo da produção e reprodução mecânica é a garantia de que nada mudará, de que nada surgirá que não se adapte.

\section{Desencantamento do mundo}

Todas as projeções e promessas da política definharam, embora ainda se conserve a diversidade de opiniões, manifestados já não tanto entre os confrontos direita/esquerda, mas entre estes e os que ocupam os lugares radicalizados, quer sejam os de direita ou os de esquerda. Ora, poder-se-ia perguntar: a que é que se deve o surgimento destes extremismos? A resposta poderia suscitar nova pergunta: e o que é que a política tem feito pelos cidadãos? A política tem oferecido um saber escasso, carente de oportunidades e alternativas; muita centrada no seu umbigo, sem capacidade de ler o futuro e de construir pontes sobre as grandes prioridades, não as de hoje, mas as do futuro. Desta forma, a vida política do presente tem sido muito arrogante, deixando a porta aberta para que a arrogância, valor dos extremistas, ganhe expressão. Uma arrogância que nasce também da deceção experimentada pelas populações, que esperam contínuos movimentos que levem a melhorias de todos os tipos, que, em boa verdade, nunca acabam por consumar-se. Isto é especialmente visível em tempos de crise, quando surgem gurus que, para atrair a população, anunciam que vão acabar com a situação anterior, prometendo mais movimento em forma de crescimento. Um crescimento que, no entanto, já não tem capacidade de construir o futuro, porque a única coisa que faz é desgastá-lo com a mesma lógica de crescimento (ROSA, 2016; 2019, p. 547). Quanto mais promete crescer para acabar com o desemprego, mais sofrem também aqueles que trabalham, visto que são arrancados repetidamente dos seus contextos de vida (SENNETT, 2001); quanto mais apelos são feitos para melhorar os rankings de educação, mais os professores e os alunos se sentem alheios ao ensino e à educação (DURÁN; DUQUE, 2019); quanto mais se consome, mais a vida é consumida, por isso, há que a renovar uma e outra vez fazendo novos consumos (GONZÁLEZ- 
ANLEO, 2014). Quanto mais as pessoas falam em conservar o planeta, mais ele é destruído com o aumento da produtividade e com um ritmo de vida que ninguém quer deixar, nem mesmo aqueles que parecem mais sensibilizados por tudo isso. Em suma, toda esta lógica de acumulação constante arranca-nos cada vez mais dos nossos mundos de vida, das nossas seguranças, para nos submetermos ao único que conta, que é a mudança permanente, segundo a qual tudo o que ontem era verdadeiro hoje deixa de ser, e assim será amanhã. E, o pior disto, é o que nos dizem, que este é o único modo pelo qual podemos construir as nossas identidades, compondo-as e recompondo-as uma e outra vez, num processo contínuo de destruição criativa (BAUMAN, 2009, p. 93; 2010, p. 21). Porque, de contrário, se não procurarmos ser cada dia mais - ou seja, mais capazes do que éramos no dia anterior, sabendo que esta capacidade, longe de se ir completando, se vai também esvaziando cada dia, pelo que a devemos continuar a preencher diariamente -, se não procurarmos tudo isto, dizíamos, seremos velhos e inúteis para o mundo.

Falta, à vida política da nossa sociedade, a consciência de que o tempo presente é frágil e incerto, mas a própria incerteza tem que ser construída de outra forma, à margem da lógica da escalada do crescimento (ROSA, 2019, p. 517). É deste saber que se deve construir o dia de hoje e partir para o futuro.

A modernidade depositou uma grande confiança na ciência, como algo que seria certo e que poderia estruturar a sociedade. Isto, de certa forma, é verdade. Porém, não é a verdade absoluta. Percebeu-se que houve e que há muita ciência a ruir. As certezas absolutas entraram em falência, dando lugar a convicções sem evidências. A confiança nesta ciência poderia ser comparada com o futuro tecnocrata, que pensava que, agindo e programando de uma certa forma, o futuro seria certo e constante. No entanto, isso foi um fracasso, pois o futuro, como já referimos, é composto por variáveis latentes e um tecido muito opaco. Portanto, a grande urgência é assumir que dispomos de um saber frágil e limitado.

A modernidade, desde os seus inícios, tem depositado a sua confiança nos processos científicos e tecnológicos e, ao fazê-lo, também lhes devolveu a sua segurança. Mas quando estes processos, como agora acontece na pandemia de Coronavírus, mostram a sua fragilidade, eles revelam-nos, como nunca tinha acontecido, as suas debilidades. Fraquezas essas que resultam de depositar todo o valor objetivo nesses processos, acreditando que neles estava a capacidade de nos redimir de todos os nossos males. Mas essa crença, se não for impulsionada por outra maior nos fins para os quais aqueles se devem dirigir, então, terão pouco valor e utilidade. Além disso, desaparecerão com a verdade objetiva que parecia sustentá-los. "Inclusive mesmo quando estão construídos tendo em conta todas as regras da ciência", 
escreveu Durkheim (1992, p. 407), “os conceitos não alcançam apenas autoridade por causa do seu valor objetivo. Para que se acredite neles, não basta que sejam verdadeiros. Se eles não se harmonizarem com outras crenças, com outras opiniões, numa palavra, com o conjunto de representações coletivas, serão negados". Dizendo de oura forma, as crenças encorajam-nos a agir num determinado sentido; vinculam-nos com um objetivo com o qual estamos comprometidos. Só assim poderemos decidir com certa segurança e confiança, "dispondo do futuro como se fosse o presente" (ARENDT, 1998, p. 264).

\section{O futuro em constante tensão}

A vida social é como uma orquestra, onde ninguém anula ninguém. Para isso, a preocupação constante deve ser trabalhar o princípio do contraditório, que passa por saber gerir as opiniões e pensamentos diferentes, porque eles mais do conflituar podem complementar, mais do que destruir podem desconstruir, e é daqui que nasce o novo, o porvir. Neste sentido, a grande missão das sociedades complexas consistiria em gerir de forma ordenada os desacordos, como quem desconstrói providencialmente para construir sabiamente.

De facto, a capacidade intacta que o futuro guarda de ser construído e a sua imprevisibilidade é o que nos atrai para ele, gerando uma forte tensão entre o já e o ainda não, embora o ainda não esteja já de forma muito latente no presente (KOSELLECK, 1993). É nesta tensão que tem que se aprender a viver.

A sociedade atual é uma verdadeira praça pública, onde a pluralidade de ofertas se entrecruza e onde a heterogeneidade de atitudes, valores e comportamentos não só é possível como aconselhável. É a complexidade social em gestão.

$\mathrm{Na}$ contemporaneidade assiste-se a grandes conquistas que não são o resultado das iniciativas de uma única pessoa ou instituição. É da constante tensão da partilha do conhecimento que advêm as grandes conquistas.

A política, em parte, cedeu o seu lugar. Como cedeu a educação, a religião, a família, e grande parte das instituições. O poder está agora na capacidade de antecipação, de antevisão. E quem o tem, tem-no de forma muito contingente.

A contingência prende-se, fundamentalmente, com as decisões que se tomam e com o modo de as tomar na prática, pois é de aí que advém o futuro. Quer isto dizer que a tensão que exige a tomada de decisões supõe um risco, uma vez que comporta uma grande dose de contingência e, por isso, têm o seu fundamento no não-saber (INNERARITY, 2011). Ou seja, 
decide-se não sobre o que se conhece, mas sobre a incerteza do futuro, o que por vezes exige um grande esforço de imaginação.

Neste contexto, pode dizer-se que vivemos numa época de crescente complexidade, em que as mudanças aceleram e alteram de um dia para o outro os âmbitos sociais, políticos, econômicos e culturais, o que desestabiliza a estrutura social que tínhamos garantida. Mas também precisamos saber que qualquer sociedade que não supere esta incerteza da mudança constante será uma sociedade desenraizada que, rompendo todos os laços com o passado e sem nenhuma perspetiva de futuro, navegará sem rumo numa crise constante. Tudo isto não significa, como se referiu, amarrar-se ao mastro do passado, para o repetir, mas, talvez, começar algo novo, com a profunda consciência do que foi, para assim enfrentar o futuro com esperança. "Quando o passado não ilumina o futuro", escreveu Tocqueville, "o espírito caminha pelas trevas" (TOCQUEVILLE, 1994, p. 278). Felizes os que foram abençoados pelos seus pais, porque também serão capazes de abençoar os seus descendentes.

Portanto, só é possível sair da complexidade e reflexividade que caracterizam as nossas sociedades com uma certa dose de confiança. Mas esta requer, tal como se afirmou anteriormente, certas crenças que a alimentem. Já passamos o tempo, que caracterizava a modernidade plena, em que os medos eram diferentes, decorrentes do sentimento de não conseguir viver de acordo com a integração necessária para enfrentar o futuro. Medos que se multiplicavam porque, tendo rompido com o mundo tradicional do passado, esta era a única alternativa possível que, no entanto, oferecia uma série de oportunidades futuras, nunca antes vistas.

Como Elias (1993) bem demonstrou, a subjetividade moderna foi construída desta maneira aparentemente contraditória e paradoxal. Pois, embora tenha sido um profundo despertar da consciência individual, tudo isso ocorreu mediante a submissão ao programa de socialização civilizado. Foi assim que essa consciência se desenvolveu ao longo da modernidade, através dos universos institucionais da família, do trabalho e da educação. Somente superando esses medos, vinculados à integração institucional exigida por esses universos, se poderia encarar o futuro, que se mostrava aberto a múltiplas possibilidades, esperando-se, assim, por um certo reconhecimento pelo que se poderia alcançar. Somente integrando-se neste marco institucional, o sujeito moderno poderia aspirar a expressar-se e a desenvolver um projeto de vida voltado para o futuro.

Não obstante, à medida que estas possibilidades se tornaram cada vez menos atraentes e claras, os medos surgiram despidos de toda a recompensa. Fato que foi denunciado desde o início como indubitável sinal de mal-estar da cultura (FREUD, 1973), antecipando o 
esgotamento do programa civilizador moderno. Uma denúncia que mais tarde se tornou muito mais persistente, à medida que toda uma geração de jovens, nascida a partir da década de 1950, se revelou abertamente contra os seus pais, vendo neles e no seu passado o exemplo de uma sociedade repressiva e, nas suas promessas de libertação orientadas para um futuro de progresso, a amostra viva de uma ideologia que ocultava aquela repressão manifesta. Tal fato foi denunciado, como é sabido, pelos intelectuais mais ilustres, ajudando a moldar o espírito de uma época inteira (BOURDIEU; PASSERON, 2001; FOUCAULT, 1999).

Sem a possibilidade de um regresso ao passado, e com as imagens do progresso cada vez mais desfocadas, deixou de fazer sentido olhar para o futuro. "No future" era o título de uma das músicas que a famosa banda de rock britânica Sex Pistols lançou em 1977 e cuja letra dizia "não me digas o que queres; não me digas o que precisas, não há futuro para ti".

Abria-se, assim, uma época em que os medos seriam outros. Não apenas aqueles relacionados com a esmagadora estrutura disciplinar das instituições, mas aqueles relacionados com a dificuldade de integração. Não aqueles derivados do necessário reconhecimento institucional, sem o qual se tornava difícil construir uma vida futura, mas de outros que se depreendem da falta desse reconhecimento, que deve ser procurado todos os dias sem desanimar, sem mais garantias do que cada um pode demonstrar.

Se os distúrbios psicológicos da modernidade estavam relacionados com a disposição de assumir as estruturas institucionais disciplinares para se ir libertando gradualmente para o futuro, os da pós-modernidade têm a ver com a dificuldade da pessoa se assumir a si própria como sujeito destinado a ser capaz e autossuficiente, uma vez desprendido dos modelos culturais passados e das orientações institucionais futuras. E, no entanto, descobre-se incapaz de ser assim quando este era o seu destino. O papel da terapia não é outro, neste contexto, a não ser procurar o reencontro do sujeito consigo mesmo; com o seu destino (EHRENBERG, 1998, p. 147). Para que este encontro, tão necessário, se concretize, propõe-se todo um programa de interiorização, com o fim de que cada indivíduo assuma a sua condição presente, livre do passado e do futuro (ILLOUZ, 2010, p. 139). Recuperado por um momento dos seus males, o indivíduo parece sair triunfante, mas assim que se endireita, sente-se desvalido como antes.

\section{REFERÊNCIAS}

ADAM, B. Reflexive modernization temporalized. Theory Culture Society, v. 20, n. 2, p. 59-78, 2003.

ADAM, B. Time. Cambridge: Polity Press, 2004. 
ADORNO, T.; HORKHEIMER, M. Dialética do esclarecimento: fragmentos filosóficos. Rio de Janeiro: Jorge Zahar, 1985.

ARENDT, H. The Origins of Totalitarianism. New York: Harcourt Brace \& Company, 1973.

ARENDT, H. La condición humana. Barcelona. Paidós, 1998.

ARENDT, H. Labor, trabajo, acción. In: ARENDT, H. De la historia a la acción. Barcelona: Paidós, 1999. p. 89-107.

ARIÈS, P. Sobre a História da Morte no Ocidente desde a Idade Média. Lisboa: Teorema, 1988.

BAUMAN, Z. Liquid Modernity. Cambridge: Polity, 2000.

BAUMAN, Z. El arte de la vida. Barcelona: Paidós, 2009.

BAUMAN, Z. Tiempos líquidos. Vivir en una época de incertidumbre. Barcelona: Tusquets, 2010.

BAUMAN, Z.; TESTER, K. Conversations with Zygmunt Bauman. Cambridge: Polity Press, 2001.

BOURDIEU, P. Meditações Pascalianas. Oeiras: Celta Editora, 1998.

BOURDIEU, P.; PASSERON, J.-C. La reproducción. Elementos para una teoría del sistema de enseñanza. Madrid: Editorial Popular, 2001.

BURY, J. La idea de progreso. Madrid: Alianza Editorial, 2009.

DELORY-MOMBERGER, C. A pesquisa biográfica ou a construção compartilhada de um saber do singular. Revista Brasileira de Pesquisa (Auto)Biográfica, v. 1, n. 1, p. 133-147, 2016.

DELORY-MOMBERGER, Christine. De la recherche biographique en éducation. Fondements, méthodes, pratiques. Paris: Téraèdre, 2014.

DUQUE, E. É possível sair do presente? Uma teoria prospetiva. In: ARAÚJO, E. et al. (eds.). Tempos sociais e o mundo contemporâneo. As crises, as fases e as ruturas. Braga: Centro de Estudos de Comunicação e Sociedade/Centro de Investigação em Ciências Sociais, 2014. p. 154-169.

DURÁN VÁZQUEZ, J.; DUQUE, E. Las transformaciones de la educación. De la tradición a la modernidad hasta la incertidumbre actual. Madrid: Dykinson, 2019.

DURKHEIM, É. Las formas elementales de la vida religiosa. Madrid: Akal, 1992. 
EHRENBERG, A. La fatigue d'être soi. París: Edile Jacob, 1998.

ELCHARDUS, M.; SMITS, W. The Persistence of the Standardized Life Cycle. Time \& Society, v. 15, n. 2/3, p. 303-326, 2006.

ELIAS, N. El proceso de civilización. Madrid: FCE, 1993.

ELIAS, N. Sobre el tiempo. Madrid: FCE, 1989.

FOUCAULT, M. Vigilar y castigar. Barcelona: Círculo de Lectores, 1999.

FREUD, S. EI malestar en la cultura. Madrid: Alianza Editorial, 1973.

GIDDENS, A. Modernity and Self Identity. Cambridge: Polity, 1991.

GONZÁLEZ-ANLEO SÁNCHEZ, J. M. Consumidores consumidos. Juventud y cultura consumista. Madrid: Khaf, 2014.

HAN, B.-C. O aroma do tempo. Um ensaio filosófico sobre a arte da demora. Lisboa: Relógio d'Água, 2016.

HUBERT, H. Estudio sumario sobre la representación del tiempo en la religión y la magia. In: RAMOS TORRE, R. Tiempo y sociedad. Madrid: CIS, 1992. p. 1-33.

ILLOUZ, E. La salvación del alma moderna. Terapia, emociones y la cultura de la autoayuda. Madrid: Katz, 2010.

INNERARITY, D. O Futuro e os seus Inimigos. Uma defesa da esperança política. Lisboa: Teorema, 2011.

JAEGER, W. Paideia. Madrid: FCE, 1996.

JANNER RAIMONDI, M. Empathie. In: DELORY-MOMBERGER, C. (coord.). Vocabulaire des histoires de vie et de la recherche biographique. Toulouse: Érès, 2019. p. $72-75$.

KOSELLECK, R. Futuro pasado. Barcelona: Paidós, 1993.

LE GOFF, J.-P. La démocratie post-totalitaire. París: La Découverte, 2002.

LUHMANN, N. Introducción a la teoría de sistemas. México: Anthropos, 1996.

M'BIATONG, J. La recherche biographique en éducation pour l'éthique. In: DIZERBO, A.; M'BIATONG, J. (coord.). Pour une éthique de l'accompagnement biographique. Paris: Téraèdre, 2019. p. 129-152.

MARCO AURELIO. Meditaciones. Madrid. Cátedra, 2004.

NOWOTNY, H. The modern and postmodern experience. Cambridge: Polity Press, 1994. 
PLATÓN. La república. Madrid: Alianza Editorial, 2003.

POMIAN, K. L’ordre du temps. París: Gallimard, 1984.

RAMOS, R. Time's social metaphors. An empirical research. Time \& Society, v. 16, n. 2/3, p. 157-187, 2007.

REVAULT D'ALLONNES, M. EI poder de los comienzos. Ensayo sobre la autoridad. Buenos Aires: Amorrortu, 2008.

RICOTTA, L. Valores do educador: uma ponte para a sociedade do futuro. São Paulo: Ágora, 2006.

ROSA, H. Alienación y aceleración. Hacia una teoría crítica de la temporalidad en la modernidad tardía. Madrid: Katz, 2016.

ROSA, H. Resonancia. Una sociología de la relación con el mundo. Buenos Aires: Katz, 2019.

ROUANET, S. Figuras do tempo. In: Ciclo mutações: o futuro não é mais o que era. Academia Brasileira de Letras: Rio de Janeiro, 2012.

SENNET, R. A cultura do novo capitalismo. Lisboa: Relógio d’Água, 2007.

SENNETT, R. La corrosión del carácter. Las consecuencias personales del trabajo en el nuevo capitalismo. Barcelona: Anagrama, 2001.

SOUZA, R.; CATANI, A. Educação escolar e educação social: uma interação a favor da cidadania. Revista Trama Interdisciplinar, São Paulo, v. 7, n. 3, p. 50-68, 2016.

SUE, R. Temps et ordre social. París: PUF, 1995.

THOMPSON, J. A mídia e a modernidade: uma teoria social da mídia. Rio de Janeiro: Vozes, 1998.

TOCQUEVILle, A. La democracia en América. Madrid: Alianza Editorial, 1994. v. 2.

URRY, J. Sociologia do tempo e do espaço. In: TURNER, B. S. (org.). Teoria social. Lisboa: Difel, 2002. p. 377-403.

VIRILIO, P. El cibermundo, la política de lo peor: entrevista con Philippe Petit. Madrid: Ediciones Cátedra, 1997.

ZAMBRANO, M. Persona y democracia. La historia sacrificial. Madrid: Taurus, 1992. 


\section{Como referenciar este artigo}

DUQUE, E.; DURÁN VÁZQUEZ, J. F. As contradições da temporalidade pós-moderna, à luz da pandemia do novo coronavírus. Revista Ibero-Americana de Estudos em Educação, Araraquara, v. 16, n. 3, p. 1713-1729, jul./set. 2021. e-ISSN: 1982-5587. DOI: https://doi.org/10.21723/riaee.v16i3.15417

Submetido em: 21/12/2020

Revisões requeridas em: 16/01/2021

Aprovado em: 11/02/2021

Publicado em: 01/07/2021 